\author{
A. Nancy Avakian \\ Robert N. Seidel \\ Empire State College \\ State University of New York
}

\title{
Introduction
}

Independent study is often an exciting opportunity for teachers of history to become involved intensely with the intellectual growth of individual students. It is also a means by which students achieve special goals ranging from developing skills in scholarship to gaining personal attention from admired professionals. Most commonly a student and professor begin independent study with a brief conversation and hand-outs such as a course syllabus, reading list, and bibliography; then matters drift until the next conference. We suggest that Empire State College's ${ }^{1}$ success with the learning contract mode of conducting independent study may offer support to those reading courses or supervised study listings that exist in most college catalogues. Indeed, learning contracts not only individualize an independent study but also help to structure and guide it. 2 Contracts may enable students to develop special abilities or to move toward stated goals by utilizing a variety of media and learning activities. Such diversity in learning resources is easily justified. The use of films and radio and television programs, in addition to printed materials, and human interaction all have value in learning and may contribute to the learning experience. Moreover, field work and life experience take on richer meaning when combined with use of printed materials and studies of concepts and theory.

At Empire State College the learning contract addresses itself to four dimensions: (1) the long range plans of the student; (2) the specific purposes of the study; (3) the learning activities to be undertaken; and (4) the means and criteria by which the learning is to be evaluated. The student's long range plans, aspirations, and goals provide a context within which the particular study in history can be viewed and understood. The beginning student, who may be uncertain about his or her future or who has had limited academic experience, may wish to explore different areas of history by way of short investigatory contracts before making long range commitments. This may be an interesting variation on the more usual practice of offering independent study opportunities primarily to intermediate or advanced students.

Before proceeding to show how themes and purposes can be organized within learning contracts, it may be useful to state some positive and negative implications for the classroom oriented program using the contract method. Many faculty members may find that contracts help structure those independent study projects they are willing to supervise. But they may also discover that contracts are a nuisance because of the increase of initial attention to the learning process as compared to the lecture and discussion method. Further, they may believe that individualized contracts deprive students of valuable group interaction. We are not arguing that contracts can or should replace traditional methods of teaching and learning, particularly where successful; we suggest that contracts may be employed within classroom structures and in combination with them. Also, while many beginning students are more pleased with group activities, some, particularly those with greater ability, interest, and commitment, may be bored and even discouraged from intensive learning by the discipline and tedium of regular classes and what may be for them the relatively superficial content of many survey courses. We have found that such students make great strides in individualized learning.

Although the students' level of academic achievement is a factor in deciding to use contracts, we have found ability and commitment to be more important prerequisites. Also, professors have to weigh the ncssible cost and 
benefit to both themselves and students relative to the work involved in becoming familiar with a new method of learning. They may discover, as we have at Fmpire State College, that individualized learning can be exciting and productive for those who undertake tne study of history as an elective, as we11 as for those who declare history as a major area of concentration.

Since history incorporates such a profound variety of human experience and behavior, a wide range of learning activities is appropriate to suggest to students. As a nractical matter, traditional teaching in most topics heavily favors printed primary and secondary materials. Yet it is well recognized that the surviving record of the human past includes elements such as architecture and works of art as well as music and participants' remembrances of the recent nast. With this in mind, we can contemplate specific purposes and themes that will, by example, illustrate the contract method of organizing independent study.

Specific Purposes

The specific purposes of a learning contract define selected categories of inquiry, tooics, or themes to be covered in the contract. Stating purposes serves as a guide to student and professor. For beginning students "gaining a basic knowledge of U.S. history, focusing on the role of women" combines a purpose with a theme. The purpose could be strengthened by adding "the student will develop a critical understanding of at least two interpretations of feminist history" or by including another theme such as "slavery, an aspect of a socio-economic system in the antebellum South." More advanced or sophisticated students may wish to pursue the purpose of "learning skills of archival research, including location, selection, interpretation, verification, and contextual analyses of primary documents" along with the themes already mentioned or with others. Finally, historians may wish to promote the development of good writing skills associated.with clarity and precision of presentation in history.

Some questions or guidelines the student and faculty member might want to keep in mind when stating the purposes of a learning contract are:

What will be the result of the learning contract? Will it be a behavior, a product, or a process?

Will the outcome relate to the terms of the student's long range plans?

Is the student equipped to achieve the stated goals within the time limits of the contract?

Are opportunities and resources available for the student to pursue these goals?

Will an informed observer, such as a work supervisor, a tutor, a field worker, or a consultant be able to aid the student to achieve the expected outcomes?

How can specific purposes and themes be incorporated in learning contracts that follow these guidelines? Let us keep in mind the principle that learning contracts are a means of articulating, organizing, and guiding study. While contracts should not be perceived as threats, they do ask professors and students to state goals more directly than those found in college catalog descriptions and many course syllabi. In this way, contracts may help allay the usual comments of students relative to learning materials prepared for them: "What was that course (or lecture/examination) all about? What did that professor expect anyway?" 
Some of the guidelines noted above are implicit in the following sample purposes, which should reoresent the result of negotiations between professor and student. For example, one student may have a desire to study women in the United States to broaden her preparation within a social work program for the bachelor's degree as well as to increase her critical tolerance for both feminist and anti-feminist viewpoints. A second student might be interested in history merely because history or a specialized area of history appear interesting, without explicit connection to any major field of study. With this attitude in mind, for example, one of our students, a policeman with a concentration in the area of criminal justice, engaged in a two-part study of U.S. history. He gained a fine knowledge of his subject and wrote a good synthetic essay on the $\mathrm{Ku} \mathrm{Klux} \mathrm{Klan.} \mathrm{He} \mathrm{also} \mathrm{completed} \mathrm{an} \mathrm{excellent} \mathrm{research} \mathrm{project} \mathrm{that}$ included a second paper, slides, maps, and an oral presentation about a particular episode of the colonial history of his region. It was based, in part, on materials collected in four local libraries and museums and demonstrated a fair aporeciation of local Native Americans during that era.

\section{Learning Activities}

Other guidelines that must be considered when determining the contract purposes and themes are better stated in the part of the contract that we at Empire State College devote to the delineation of learning activities. This section of a learning contract must also be specific. If particular books are to be read, they should be listed. Faculty members may wish to consider the appropriateness of primary as opposed to secondary sources, historical as opposed to contemporary perspectives, and other alternative frames of references. Some professors may want to suggest bridges between theory and practice or connections among several disciplines such as history, sociology, and economics. On the other hand, after a faculty member provides an initial bibliography, he or she may wish the student independently to develop it further. In this way, the student has an opportunity to become familiar with the literature available in the field.

If a student is to choose from several alternatives, these should be mentioned. For example, a learning contract may indicate that a student has a choice between conducting a case study or carrying forward in-depth historiographical research in local history. Either project may be acceptable, but both should be mentioned as alternative approaches.

If individuals in political offices are to be interviewed, the names of the interviewees, and possibly their offices or responsibilities, might be indicated together with the purposes or objectives of the interviews. Needless to say, such a contract might also necessitate the incorporation of the elements of study relative to conducting interviews or gathering research dat.a. Thus the student pursuing feminist history could speak to individuals with memory of the suffragist movement, women who have defied tradition and social practice to attain prominent positions, leaders of political parties, and both advocates and detractors of the Equal Rights Amendment. In addition to readings, the ESC student who developed the excellent local history project interviewed local historians and archeologists, learning perhaps more quickly and authoritatively than in other ways various interpretations of the event under scrutiny. Moreover, he discovered documents and other materials that otherwise might have eluded his investigation. The contract allowed, indeed encouraged, this fruitful search.

Meetings between students and faculty members should be scheduled specifying particular times and dates as well as purposes, even if only to check progress. Dates for submission of papers or examinations should be included. Some contracts may suggest biweekly conferences that average an hour and a half to two hours in duration. Empire State College is flexible, permitting students 
to engage in contracts that begin or terminate almost any time during the fortyeight weeks of the year when the College is in session. However, traditional semester or trimester programs require that the contracts specify dates for submission of papers, final conferences, and examinations to meet registrar's deadlines.

A $\log$ is a useful tool whereby a student may record activities pertinent to his or her learning. Again, we urge specificity: individuals contacted should be identified, bibliographies should be recorded, events attended should be listed, and field work accomplished should be identified. An important aspect of the $\log$ is the identification of significant ideas encountered. However, a $\log$ need not, and indeed should not, be a diary or intimate revelation of personal matters.

The learning activities should be specific enough for the student to proceed independently, yet flexible to permit the student to explore further. There should be ample opportunities for the student to display initiative and creativity. Moreover, activities should be appropriately demanding for the student's academic status and level of development, a determination often best made by the professor but also facilitated by student participation in contract negotiation.

\section{Means and Criteria of Fvaluation}

At ESC fulfillment of a learning contract means that there is agreement between the student and the faculty member that the objectives of the learning contract have been accomplished. Although each institution has its own method of recording evaluations, there is general agreement that evaluation of learning has several components. A continuing evaluation occurs during studentprofessor dialogues. Then evaluations are made of products and in terms of the student's reproducible yet internalized learning. Nonethless, the substance that is to be evaluated should be described in the contract as clearly as possible, whether it be a book review or critique, paper, log, journal, work samples, oral presentation, or artistic performance. Examination scores may also be used. Learning contracts should also be explicit about the means and criteria for evaluation. Questions such as the following must be given attention.

Is the process of learning to be stressed?

Are special techniques to be mastered?

What ideas or concepts are anticipated?

Is the objective of the learning contract concerned with the student's ability to analyze and critique a concept or is the purpose a synthesis and application of the concept to a relevant situation?

At ESC an evaluation of a learning contract is in narrative form. It most often describes a technique a student has mastered or an application of a concept to a pertinent situation. Usually the evaluation identifies the student's growth and strengths as well as those areas that may need improvement in future studies. Such evaluations as we do continually are not, however, incompatible with traditional marking techniques and the strictures of computerized record keeping. Yet qualitative evaluations leave more substantial "tracks" for students and others. 
Independent mode of study, the faculty member should consider himself or herself not necessarily or only as the teacher, but more as the coordinator or facilitator of the student's education and self-learning, making available as many alternatives as possible. While we assume that careful planning precludes major changes later in the execution of the learning contract, a student, in consultation with the faculty member, should have the opportunity to modify a contract for sufficient cause. Therefore, ESC legitimates contract amendments that are properly executed.

While many institutions of higher education have utilized independent study as a mode of facilitating learning, there exist some concerns and problems relative to learning contracts that are endemic to the institutions themselves. At ESC we have identified the following as areas of concern in connection with study via learning contract:

Inability of some students to work independently, i.e., via the learning contract.

Inability of some students to seek out or analyze community resources.

Inflexibility or lack of creativity on the part of some faculty members to help in the development of a learning contract that meets the needs of a particular student.

Too many students for a faculty member to serve or guide effectively.

In this paper we have slipped back and forth between the practice involving independent study and individualized learning at Empire State College and the possible use of the learning contract technique to improve, expand, or articulate independent study in other colleges and universities. We have tried to indicate some advantages and possibilities of the contract. Historical study--perhaps one of the most individualistic of academic disciplines--is, it seems to us, a proper field for contemplating this mode of college learning. With due consideration for rigor and responsibility, and with attention to the often subjective nature of history and the outcomes of its study, individualized study organized under learning contracts may serve as a positive catalyst for the student as well as the faculty member.

\section{SAMPLE LEARNING CONTRACT}

\section{Specific Purposes:}

The student will (1) conduct an investigation into historiography, the nature of historical inquiry, methodology, and the variety of historical scholarships. In addition he will (2) develop a project involving archival research and the writing of a paper on a specific question in the history of U.S. foreign policy.

\section{Learning Activities:}

1. The student will read the following (or approved substitutes) and discuss them with the mentor: Louis Gottschalk, Understanding History; E. H. Carr, What is History?; Marc Bloc, The Historian's Craft; J. H. Plumb, The Death of the Past; Hans Meyerhoff, ed., The Philosophy of History in Our Time, or Fritz Stern, ed., The Varieties of History; J. H. Hexter, Doing History. He will write five papers covering the following:

a. A review of Gottschalk on historical research methodology.

b. A comparison of Carr and Bloc on attitudes toward history and its uses.

c. A critical review of Plumb. 

d. A comparison of five historians, representing five different "schools of interpretation" or philosophic positions (using. Meyerhoff and/or Stern).
e. Hexter's goal in his critical essays on history.

2. In the second activity of this contract, the student will produce a major essay based on primary and secondary materials, both published and archival. He will focus on U.S.-British relations in 1939-1943, seeking in particular to investigate the trip of Wendell Willkie to Europe as personal representative of President Franklin D. Roosevelt. He will:

a. Assemble an annotated bibliography of books, articles, and other materials (both primary and secondary) dealing with U.S. diplomacy, U.S.British relations, U.S. politics, and other aspects that will illuminate the context of the specific episode under inquiry.

b. Define the focus of research.

c. Gather information, including results of archival research, taking substantive and accurate notes.

d. Weigh the significance and validity of information and the hypotheses that are generated by it.

e. Identify and evaluate historical interpretations of the event under scrutiny.

f. Come to his own considered judgments, conclusions, and questions for further study on the subject.

g. Prepare a typed final draft of the manuscript essay showing, among other things, adherence to accepted rules for notation and documentation using Kate Turabian, A Manual for Writers of Term Papers, Theses and Dissertations, as a guide to study.

He will consult with the mentor during the development of research and of the essay through its drafts.

\section{Evaluation}

The mentor will evaluate the student's learning in this contract on the basis of oral and written presentations. He expects the student to gain a fair comprehension of historical change in doing history, the nature of historical inquiry, methodology, and the varlety of historical scholarship. He also expects the student to gain specific knowledge of archival research and to produce a wel1researched essay on the selected topic in U.S. diplomacy. The essay must effectively demonstrate the connection between the presentation on the specific topic and (a) its broader context and (b) at least two conflicting interpretations of U.S.-British relations and of U.S. diplomatic history.

\section{RELATED WORKS OF INTEREST}

A. Nancy Avakian, "Writing a Learning Contract," in Dyckman W. Vermilye, editor,

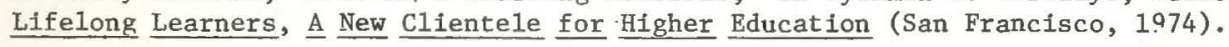

Robert N. Seide1, "Doing Humanities in an Individualized Education/Self-Study College Environment," printed by Empire State College for distribution to the Faculty, December, 1974-January, 1975. Copies of this paper may be obtained from Professor Seidel while supplies last.

\section{NOTES}

${ }^{1}$ Empire State College, the statewide college-without-walls unit of the State University of New York, was founded in 1971.

2 Many institutions of higher education are utilizing the learning contract. They include New College in Alabama, Metropolitan State University at St. Paul, Minnesota, and the independent student program at Rochester Institute of Technology. 